\title{
ENTREVISTA
}

\section{ENTREVISTA COM MICHAEL APPLE}

RICARDO GONÇALVES SEVERO'

(Favor Informar Orcid) ORCID: https://orcid.org/0000-0001-8413-7159

RODRIGO DUQUE ESTRADA"

ORCID: https://orcid.org/0000-0002-7509-6911

I Universidade Federal do Rio Grande, Rio Grande, RS, Brasil.

II Universidade de York, Reino Unido.

Ricardo Gonçalves Severo - Doutor em Ciências Sociais (PUCRS). Professor do Programa de Mestrado em Educação da Universidade Federal do Rio Grande (FURG). E-mail:< rgsevero@furg.br $>$.

Rodrigo Duque Estrada - Doutorando em Política na Universidade de York (UoY). Mestre em Relações Internacionais pelo Programa de Pós-Graduação San Tiago Dantas (UNESP, UNICAMP e PUC-SP).

E-mail:<rodpanzera@gmail.com >.

A obra de Michael W. Apple é uma das mais relevantes para auxiliar-nos a pensar as questões educacionais e suas relações com a política e a sociedade em geral, partindo de uma perspectiva crítica. Autor de extensa obra acadêmica, suas análises buscam relacionar uma preocupação teórica com o ativismo na educação em nível internacional $(2008 ; 2011 ; 2013)$.

Seus escritos nos auxiliam a compreender como o ambiente escolar pode servir como espaço de reprodução de valores hegemônicos na sociedade através do currículo (2006) e, ao mesmo tempo, como espaço de produção de práticas de resistência e produção de relações democráticas (1997; 1997a).

Ainda, a partir da análise do desenvolvimento político nos Estados Unidos e considerando os padrões internacionais de formulação de políticas, o autor compreende que vivenciamos o que denomina como modernização conservadora (2006a, 2017), o qual conta com um leque de alianças de distintas visões de mundo (neoliberalismo, neoconservadorismo, autoritarismo populista e, de modo pragmático, uma classe média tecnicista). A partir da análise 
desse leque de alianças e das formas de produção de narrativas e políticas, é possível compreender possíveis desdobramentos, em especial no que diz respeito à educação.

Em julho de 2019, Michael W. Apple esteve em Porto Alegre para a realização de uma atividade junto à UFRGS e também à PUCRS. Aproveitamos essa oportunidade para conversarmos com o professor Michael sobre a ascensão do populismo autoritário no Brasil, considerando os leques de aliança e possíveis desdobramentos, sua compreensão sobre uma educação democrática, os possíveis motivos dos ataques à imagem de Paulo Freire e possíveis formas de resistência, que apresentamos a seguir.

Como o senhor deve saber, Paulo Freire, patrono da educação brasileira, hoje é um dos símbolos mais atacados pelo bloco reacionário no poder, especialmente pelos autoritários populistas e neoconservadores. Imputam ao seu método, que consideram como dominante na educação brasileira, a razão de seu "fracasso", utilizando, para "comprovação", resultados comparativos internacionais. Por qual razão o senhor pensa que isso tem sido feito?

Precisamos lembrar que Paulo Freire não está sozinho nisso. Ele é o símbolo de mobilizações maiores que remontam há quase meio século. Então, mesmo que não fosse Paulo Freire, poderia ter sido outra pessoa. Ele simboliza tudo aquilo em relação ao qual essas pessoas são contrárias: democracia como algo denso, como vindo das pessoas que são oprimidas. Ideologicamente, o grupo e a aliança de Bolsonaro enxergam o empobrecimento de maneira distinta de Paulo Freire.

Freire veria a pobreza como algo que está errado na sociedade. Para Bolsonaro e outros, não se trata da pobreza como um produto social, mas um problema individual. Então, para esses grupos da direita, é como se as pessoas não trabalhassem suficientemente, como se a sociedade desse a todos as mesmas oportunidades, e as falhas se devessem a pessoas viciadas ou pessoas afrodescendentes e que não trabalham o suficiente. Portanto, devemos dizer que, em grande medida, Paulo Freire é utilizado como um instrumento mobilizador para dois grupos: o primeiro são os pobres e os educadores críticos, e o outro, mobilizado pela direita contra tudo aquilo que creem ser errado. Portanto, se podem destruir a memória e a reputação de Paulo, isso abre um espaço para eles colocarem suas próprias figuras icônicas, que podem ser o exército - sabemos do amor que Bolsonaro tem por esta instituição. Ou podem também deixar isso em branco e dizer: "sigam-nos". Isso é um pouco do que entendo que esteja ocorrendo. Mas também tem a ver com raça. 
Paulo Freire era muito explícito, especialmente no início e final de sua carreira, com relação à importância de enxergar as pessoas mais oprimidas da sociedade. E ele conseguiu compreender cada vez mais sobre como grupos específicos são mais oprimidos que outros. E isso representa uma ameaça à branquitude, à supremacia branca. E se você prestar atenção no argumento que Bolsonaro e sua aliança estão fazendo, em grande medida, isso também inclui ataques a grupos indígenas e a pessoas negras. Portanto, tudo aquilo em relação ao qual eles são contra, está incorporado nos escritos e trabalho de Paulo Freire.

\section{Quais são os interesses dos grupos conservadores no âmbito da educação?}

Isso é complicado. Escrevi sobre isso no livro "A Educação Pode Mudar a Sociedade?" (2017) e também num livro anterior chamado "Educando à Direita" (2006a); ambos foram traduzidos no Brasil. Não se trata de uma única coisa. Existem quatro grupos no processo de modernização conservadora, isto é, olhando para o futuro, uma economia capitalista inconteste, olhando para trás, um tempo em que todos acreditavam exatamente na mesma coisa e eram cristãos.

O primeiro grupo são os neoliberais. Estamos já familiarizados com suas tendências destrutivas, querem proteger a esfera privada. Para eles, o Estado é ruim. Ironicamente, eles são os últimos leninistas: o Estado só é bom morto. Eles querem a privatização, a competição. As escolas estatais são ineficientes, os professores são maldosos ou não trabalham suficientemente. Há um segundo grupo que deseja um Estado forte, é o grupo por trás do Escola sem Partido, que gostaria de chamar de neoconservadores. Eles têm um sentimento arraigado de um passado imaginado, onde todos aceitavam exatamente a mesma cultura e história. Então, para eles, há ênfase demasiada no currículo sobre minorias, mulheres, pessoas trans. Portanto, estes são os "outros" que não estão a bordo nessa visão bastante conservadora. Isso é estranho, um Estado neoliberal fraco e um Estado incrivelmente forte e controlador com relação à cultura, para os neoconservadores. A aliança é tensa.

O terceiro grupo que cresce rapidamente no Brasil é o que chamo de populismo autoritário. São conservadores religiosos que creem que o problema é que as pessoas se desviaram de Jesus, com uma interpretação conservadora a respeito do que consideram o único livro que possui toda a verdade: a bíblia cristã.

O quarto grupo é uma fração específica da classe média, e eles conseguiram cavar uma esfera de autoridade dentro do 
Estado, especialmente no que tange a cálculos, testes, padronização, etc. Nesse sentido, os professores devem prestar contas e serem responsabilizados ${ }^{1}$. Esse é o grupo que pensa: sabemos dizer quão bom é o professor apenas olhando suas pontuações. Portanto, não é apenas um grupo e é isso que torna difícil contê-los, porque existem quatro elementos nesse processo, que fizeram compromissos táticos uns com os outros. Portanto, imagine os neoliberais, com sua visão de um Estado fraco formando uma aliança com pessoas que querem um Estado muito forte que controle a história e a cultura, que demoniza quaisquer ganhos realizados para as mulheres, grupos minoritários, grupos de deficientes. Para eles, esses grupos são os "outros". Portanto, essa é uma questão mais complexa, pois quando identificamos que não se trata de uma coisa única, isso significa que precisamos pensar em estratégias que serão variadas, mais integradas em torno de alianças, ao invés de dizer que se trata sempre de neoliberais. Portanto, o prefeito do Rio de Janeiro ${ }^{2}$, como exemplo, ele é um neoliberal, mas é também, primeiramente, profundamente alinhado com grupos conservadores religiosos. E muito do financiamento para grupos conservadores religiosos no Brasil advém dos Estados Unidos. Novamente, é uma questão difícil, dediquei muito tempo pensando como esses grupos formaram uma aliança.

Penso que devemos olhar atrás, pois não é algo recente, demorou 50 anos. É uma combinação tradicional de anti-comunismo, preocupações sobre Lula, sobre o PT, não apenas sobre a corrupção, mas com essa visão da sociedade que eles pensam que seja stalinista. Isso é bizarro! Escolheram uma leitura equivocada da história. Não há nada stalinista em querer que os pobres tenham uma voz, não apenas individualmente, mas coletivamente. Não há nada stalinista quando afrodescendentes brasileiros afirmam, repetidamente, que "não somos representados no currículo das escolas". Então, isso se transforma numa questão muito mais difícil do que a esquerda tradicionalmente admite. Não é apenas sobre classe, é uma agenda racial e de gênero.

Não gosto de sair por aí dizendo isso, porque eu mesmo estou na esquerda do espectro político, mas acredito que as respostas tradicionais sobre quem esse grupo é, precisam ser pluralizadas. Precisamos dizer que esse processo começa não com Bolsonaro, nem com Lula, começou bem antes da ditadura militar. Demorou 50 anos para que esses grupos se juntassem e, infelizmente, pode demorar um período semelhante até que os grupos de oposição ajam em conjunto, apesar de também estarem se mobilizando por 50 anos, às vezes com sucesso, como demonstra o caso de Porto Alegre ${ }^{3}$. 
Jair Bolsonaro e seus filhos parecem ver Trump como um modelo a ser seguido. Uma das coisas que observamos nos dois casos é o encorajamento contínuo da polarização, seja no Twitter ou em qualquer outro veiculo de comunicação. Que diferenças e semelhanças você consegue observar nessas duas figuras?

Ambos estão trabalhando a partir de sentimentos populistas. Isso não significa que são populistas. Estão utilizando retórica populista e, ironicamente, são seguidores da teoria gramsciana, que afirma que as pessoas não são estúpidas ou fantoches. Elas compreendem coisas acerca de suas vidas. Portanto, é verdade que há miséria, que as pessoas sentem que não possuem uma voz, especialmente se levarmos em conta uma crise econômica global.

É verdade que as pessoas acreditam que algumas das coisas que dão sentido às suas vidas, como a religião, é vista como desimportante por outras pessoas. Tudo isso é verdade, mas isso não quer dizer que seja ruim, pois há elementos de bom senso. E o que os grupos dominantes fizeram historicamente, especialmente grupos populistas autoritários, é alcançar retoricamente a consciência das pessoas e conectar a si próprios com a raiz do entendimento popular sobre o que está ocorrendo. Portanto, Bolsonaro e Trump conseguiram ser atores nos dois sentidos deste termo: colocar uma máscara, agir como um verdadeiro populista, e puxar as pessoas sob sua liderança. É uma capacidade retórica, e creio que esquecemos o quão talentosos Bolsonaro e Trump na verdade são, pois são muito talentosos com a mídia.

Mas não são apenas eles, Bolsonaro e Trump. São pessoas representativas de um movimento muito maior e agressivo. Não haveria Trump sem os milhões de dólares que vêm dos magnatas da mídia, dos grupos religiosos fundamentalistas, que selecionaram tanto Trump quanto Bolsonaro e os empurraram para frente. Há semelhanças, portanto, em termos dos grupos que os apoiam e suas habilidades de dizerem o indizível e fazer parecer racional. Essa é a fórmula fascista tradicional. Se você analisar os discursos de Mussolini, a animação com suas mãos e o corpo... isso é o Trump! Bolsonaro é menos corporal, mas se você prestar atenção, ele é muito inteligente com relação aos temas que escolhe. Há grandes diferenças: Bolsonaro tem ligações com o exército e com a violência. Trump possui ligação com violência contra as mulheres, é um estuprador, foi acusado várias vezes disso, e há muitas mulheres que já o acusaram de coisas terríveis. Acredito que muitas dessas acusações sejam verdadeiras. Porém, Bolsonaro possui outro tipo de violência: a violência realizada por Pinochet no Chile, da ditadura militar no Brasil. Mas ao invés de chamar isso de violência, ele a chama de ordem: "nós traremos de volta a ordem". Trump prefere 
o caos, ele quer ser um rei, e sua retórica é quase de realeza, perversa, racista, mas ele quer criar caos. As pessoas dizem: ele está dizendo a verdade. Isso também faz parte da retórica de Bolsonaro, mas por trás dessa perversidade, reside não apenas a ameaça, não apenas de desordem, mas de violência militar constante.

Então, quero tomar cuidado com isso, pois meu entendimento de Bolsonaro advém da tradução. Tenho maior facilidade para analisar Trump porque falamos o mesmo idioma, enquanto aqui, dependo da tradução de amigos para analisar Bolsonaro. Creio também, que seus filhos possuem mais poder do que os filhos de Trump. Mas ambos mobilizam as conexões familiares. Então, o que você faz é apresentarse como um homem de família, e isso é atraente para conservadores religiosos, mesmo que pensem que sejam violentos. Há também semelhanças e diferenças sobre como a religião os apoia.

A direita religiosa nos Estados Unidos sabe que Trump é um predador sexual, e dirão que "Deus trabalha através de seres humanos imperfeitos”. É mais complexo, aqui. Há uma religião da prosperidade, aqui, que é mais forte do que nos Estrados Unidos, onde formas pentecostais se tornam politicamente interessantes e integradas ao governo. Então, há coisas que não entendo, mas a pergunta que surge é: por que os conservadores religiosos dão tanto apoio a coisas que são militares, que instilam violência. Como é possível que Jesus Cristo seja utilizado para apoiar violência contra as mulheres, um Estado que voltará à violência, uma economia que é violenta, a violência contra os indígenas, etc. Como isso se justifica? Não estou preparado para compreender as diferenças do modo como cada regime utiliza a religião, mas sei que não conseguiremos compreendê-los sem compreender como a religião é utilizada no Brasil.

Tivemos um ciclo de neoliberalismo nos anos 1990 com o governo do Fernando Henrique Cardoso e depois tivemos um periodo que alguns chamam de liberalismo social sob o PT com o governo Lula. Alguns dizem que seu governo reverteu politicas neoliberais enquanto outros disseram que foi uma adaptação do liberalismo. Agora, temos um novo ciclo do neoliberalismo, que parece mais agressivo. Você enxerga alguma diferença nesses ciclos, ou são os mesmos agentes?

Existem sobreposições com relação aos agentes, mas há também novos agentes. Primeiro, lembremos que a direita jamais dorme. Por isso, sou sempre cauteloso com celebrações. Portanto, ao mesmo tempo em que ocorria o Fórum Social Mundial em Porto Alegre ${ }^{4}$, enquanto o PT estava no poder, eu era uma das pessoas divulgando isso fora do Brasil. Eu vim aqui dar uma palestra de 
abertura do Fórum Mundial da Educação e todos estávamos batendo palmas. Porto Alegre era o centro da resistência, era o lugar que poderia dar uma lição ao mundo. Há inclusive vídeos meus dizendo isso, que Porto Alegre era a professora do mundo. Não éramos românticos, mas passaram-se 15 anos e pensávamos que era permanente. Nada do que é progressista é permanente. Portanto, a direita aprendeu com a esquerda. Aprendeu a mobilizar as pessoas pobres. Copiaram o Lula, odiavam a Dilma, que é uma mulher, por motivos que também são complicados. Mas a esquerda, infelizmente, estava demasiadamente congratulatória, não compreendia bem o suficiente, nem mesmo eu, que por cerca de 20 anos, após a saída de FHC, quando Porto Alegre parecia ser o modelo para o mundo; a direita se mobilizava trazendo novos agentes. Tornou-se a salvadora da religião, compreendeu profundamente como utilizar a mídia, de maneira brilhante.

Claro, se você tiver a TV Globo em seu bolso e também milhões de dólares, é muito mais fácil; algo que a esquerda jamais teve. Então, a direita passou a mobilizar a partir da criação de novas agendas que se ligavam à consciência das pessoas. Construíram uma aliança mais ampla e criaram aquilo que chamei em minha palestra mais cedo de névoa epistemológica: negando constantemente a existência de problemas reais e culpando os governos anteriores (exclusivamente do PT), retomando, às vezes, ao discurso liberal, nessa fusão com uma estratégia linguística brilhante que dizia: "somos a favor da liberdade e da democracia, mas vamos mudar o sentido da democracia".

Eles mantiveram a palavra democracia, que é uma palavra nossa, uma palavra progressista, assim como a palavra liberdade. Então, eles disseram: "vamos pegar o significado que o PT ou outro grupo dá a esses termos, mantemos a palavra e jogamos fora o significado". Esta é uma distinção que fazemos entre democracia densa e rasa. A primeira, sendo orçamento participativo, escola cidadã, mobilizações de baixo a partir de pais, estudantes, a comunidade e professores, todos juntos construindo a política educacional. Essa é a democracia densa; se ela te afeta, você pode participar dela. Eu gosto dessa ideia, é minha teoria também. Então, eles mudam isso: agora a democracia se resume a escolha individual dentro do mercado. Vamos fazer com que os professores compitam, transformá-los em mercadoria, vamos fazer das escolas produtos que compramos e vendemos, comercializar o currículo. Tudo isso seria parte da democracia, dar informação aos pais, assim eles podem escolher no mercado, e se fizerem uma escolha ruim, isso não é nossa culpa, é apenas como o "afrodescendente preguiçoso" no Brasil, que fez a escolha errada, não havendo qualquer responsabilidade 
ética ou social. É o mundo como um grande supermercado. Portanto, eles usam a estratégia, de forma brilhante, de tomar nossa linguagem, mudando seu significado e a mobilizando. É como se enchesse uma garrafa com água nova ${ }^{5}$ e esta dizer: "sou profundamente democrática", pois alguns pais dizem que Deus precisa voltar.

Assim, daremos a eles uma escolha, e caso você discorde, você não estará sendo democrático. Se você pensar que povos indígenas não devem ter uma voz, mas sim os plantadores de soja, que são grandes contribuidores da direita, que não são pequenos produtores, mas os grandes conglomerados... Se você achar que você está defendendo o meio ambiente, você não está sendo democrático, pois são criadores de emprego, e você está como um bebê mamando nos seios do governo. Portanto, eles fizeram um conjunto de coisas brilhantes. Sim, há semelhanças, mas apesar de eu ser profundamente contra o que fizeram, creio que temos muito que aprender com eles, sobre o uso da mídia, da forma como mudanças linguísticas funcionam e aprender sobre como se deve mobilizar as pessoas que jamais votariam em você há 20 anos atrás.

Com relação ao projeto Escola sem Partido, fundado em 2004, mas apenas em 2014 comecou a crescer. Miguel Nagib, o idealizador do projeto utiliza uma retórica onde a educação é entendida como uma mercadoria e os direitos humanos não devem ser ensinados na escola, pois questões morais seriam um assunto da familia e da igreja. Especialmente após a eleição de Bolsonaro, esse grupo e essa retórica começaram a ficar mais ainda agressiva, em especial contra os professores. Como podemos demonstrar que esse projeto não é neutro e possui ideologia?

Bem, para mim, não existe “educação neutra”. E não digo isso no sentido negativo: a educação, por definição, é um ato moral, é um ato de influência. Isso significa que precisa ser justificado em termos éticos e políticos. E qualquer pessoa que finja que a educação seja neutra, de que o conhecimento lá fora é neutro, está se esquecendo de que alguém construiu uma rede, e deixou essa rede cair no universo do conhecimento. Dependendo do tipo de rede que você arremesse, você pescará algo, o conhecimento. Tomemos como exemplo a história da escravidão no Brasil. Como é possível falar de forma neutra dessa história? Podemos criar um vácuo epistemológico e negar que tenha ocorrido, ou dizer, como alguns desse governo, que a escravidão "ajudou a população negra, os civilizou". Acho que isso é profundamente repugnante. E eu jamais gostaria que alguém fosse professor dizendo algo tão desgraçado. Estou utilizando, portanto, um exemplo forte de propósito. 
Porém, há debates sobre o que conta como conhecimento importante. Existe uma ficção da cultura comum. Dizem que temos uma cultura comum. Nenhuma nação do mundo possui uma cultura comum. Há tradições linguísticas diferentes, algumas indígenas, outras não. A classe trabalhadora é dinâmica, ela transita. O Brasil possui uma população internacional. Portanto, a "cultural comum" está sempre em movimento. Não há nada de estável nela. Isso quer dizer que algumas pessoas, da maneira mais democrática possível, precisam tomar decisões. E tais decisões precisam tentar incorporar todas as vozes que forem possíveis. Então, haverá debates. E essa ideia do "comum" também é uma forma de exclusão, que não é um processo neutro. Precisa ser justificado, não dizendo que há esferas separadas, ou qualquer coisa que seja controverso, como a moralidade de casa... Deixe-me dar um exemplo de minha própria experiência.

Quando eu comecei a dar aula, ensinava em bairros populares, nas escolas que havia frequentado quando era uma criança pobre. Depois, dei aula em uma comunidade rural que possuía uma sede ativa da Ku Klux Klan (KKK). Não sei se as pessoas que verão esta entrevista conhecem a história do KKK nos Estados Unidos. Era um grupo juridicamente legal (em alguns lugares ainda o é, infelizmente, o que não quer dizer que não seja uma desgraça). As marchas que Trump apoiou foram em parte organizadas por grupos supremacistas brancos, dentre os quais o KKK. E era decisão da comunidade local. Quando eu e outros professores pesquisávamos sobre a comunidade, descobrimos que houve linchamentos, assassinatos e enforcamento de pessoas negras na região sul do Estado onde eu dava aula.

Essa comunidade tinha uma posição semelhante ao ESP, de que a escola não deveria ensinar nada controverso, como a moralidade. Questões "controversas" deveriam ser ensinadas em casa. O que descobrimos é que havia documentos escondidos de escrituração das casas dessas comunidades que diziam: "proibido vender para negros, italianos, judeus ou imigrantes”. Então, quando descobrimos isso, tivemos longas conversas com as crianças sobre o que isso representava para a comunidade, se ainda existia isso... Esse tipo de coisa precisa ser ensinado.

A comunidade tentou demitir todos os professores. Se utilizarmos esse exemplo, se dissermos que a cultura comum jamais deve lidar com a moralidade numa sociedade que é racista, onde as mulheres não têm controle sobre seus corpos, onde os povos indígenas perdem suas terras e às vezes suas vidas, bem como o meio ambiente, estaremos sendo coniventes com esse tipo de violência. Onde agora 
parece estar ok bater em pessoas trans e gays, acho isso difícil de justificar. Creio que isso seja imoral. Podemos dizer: "não ensine isso, não debata". Não consigo ver qualquer maneira substantiva ou moral para justificar a ignorância dessa forma. Portanto, entendo que o argumento seja falso, retórico e profundamente perigoso. Bem como deixa praticamente impossível para que professores possam conectarse com a realidade vivida pelos próprios estudantes. Eu trabalho com pais conservadores o tempo todo.

Quando se explica a eles perguntando se há pessoas gays na família, ou se vivem numa comunidade que é demasiadamente quente, onde não há água suficiente, e se questiona se acreditam que não haja mudança climática, eles começam a adotar uma posição mais progressista. A escola precisa ser um ambiente onde os estudantes possam debater honestamente, onde se pode focar na realidade, se não, posso te dizer que do ponto de vista prático, você perderá todos os seus estudantes. E, constantemente, os estudantes estão dizendo que odeiam a escola.... Vou concluir com mais um exemplo.

É frequente que esse mesmo grupo queira avaliações, porque acreditam que há conhecimento neutro que possa ser mensurado. Nos Estados Unidos, os professores são pagos conforme seu desempenho, em muitos Estados. A pesquisa é fabulosa, se entrevistam as crianças quando suas notas aumentam e as questiona: "Você acertou as perguntas em literatura, você gosta de ler? Você tem vontade de ler livros?". Estatisticamente, uma boa parte dirá: "Não gosto de ler, não tem nenhuma relação com a minha vida." Se este é o tipo de escola que você quer, onde não há qualquer conexão com a cultura vivida da maioria das crianças, que vivem num mundo que talvez você queira negar, mas que é real, então faça isso, aprove o ESP, e então posso garantir que você criará uma sociedade na qual os estudantes serão mais resistentes, os professores ficarão ainda mais bravos... Se este é o tipo de escola que você quer, então faça o que está fazendo. Então, nós temos pesquisa muito robusta comprovando que, na verdade, isso cria mais problemas do que soluções.

Professor, nós desenvolvemos no interior do Rio Grande do Sul um projeto intitulado "Debates Escolares", que visa criar um espaço horizontal onde os alunos tenham liberdade em escolher o que queriam debater. Alguns temas como racismo, machismo, a duração de tempo que eles têm para comer, foram debatidos porque é o tema que eles queriam. Então, começaram a fazer, por exemplo, podcasts para discutir esses temas. Minha pergunta é: esses tipos de projetos têm importância para combater os novos projetos conservadores e neoliberais? Com isso, minha principal preocupação é aquilo que você discutiu de manhã, sobre 
a esquerda retórica. Ela não coloca os pés no chão, mas ao mesmo tempo, me preocupo em ser um secretário da realidade6 das pessoas, porém temo perder a crítica nas escolas por causa disso.

Entendo. Por isso que neste livro (Pode a Educação mudar a sociedade?), uma das coisas sobre as quais falo é que ambas as palavras são importantes: crítica e secretário. Às vezes, penso que somos modestos demais. Pensamos que não devemos impor qualquer senso crítico. Nos sacrificamos para estudar. Agora, conheço coisas que não conhecia quando era professor na escola primária ou secundária. Agora, sou professor universitário e também faço filmes, vou às escolas ver as crianças e até nas prisões para entrevistar a juventude.

Portanto, como disse na palestra da manhã, acredito fortemente no poder da mídia. Mas uma das coisas que se torna importante é que a gente não perde essas habilidades. As pessoas se sacrificam para conquistar tais habilidades. Eu venho de uma família de imigrantes muito pobre, cresci numa favela, sou da primeira geração que concluiu o ensino secundário na minha família. Então, houve um esforço muito grande da parte de algumas pessoas para que eu pudesse ter conhecimento. E creio que seja um desastre se a gente não utilizar esse conhecimento.

No entanto, precisamos usar isso de maneira que seja respeitável, onde a gente escuta críticas direcionadas a nós mesmos... Quando vou a uma escola fazer um filme ou debate, pra tratar da "escola da esperança", projeto do qual participarei ${ }^{7}$, mas também, se eu tiver uma crítica, direi em linguagem não acadêmica, mas tentarei fazer com que as pessoas pensem sobre isso na forma de um paradoxo, contradição: é isso que você quer realmente? Já pensou no que pode acontecer? Como você vai defender isso? Isso faz parte do meu treinamento enquanto analista crítico de políticas públicas. É tanto desrespeitoso não perguntar sobre isso, pois as pessoas não são estúpidas, quanto não querer ouvir as críticas de volta. Precisamos devolver o que aprendemos. Mas precisamos fazer isso de modo que também sejamos ensinados a partir de baixo, pois talvez essas pessoas já tenham pensado sobre esse problema, ou já estão conscientes da questão. Então, quando estou nas escolas, isso é algo que tento praticar constantemente. Vou dar um último exemplo:

Meu pai era tipógrafo, eu fazia faculdade à noite e trabalhava como repórter durante o dia. Depois, sempre levava meus livros para o meu pai, ele ficava muito orgulhoso, pois eu era o primeiro filho e todos haviam se sacrificado para eu ir para o ensino médio e, depois, à universidade. Eu dizia ao meu pai que sentia falta de estar numa 
sala de aula, pois quando ensinava uma criança a ler, sentia orgulho disso. Então, eu pensava que talvez devesse parar de escrever, gostaria apenas de um prêmio nacional por um dos meus livros. Meu pai me olhou e disse: "O que há de errado contigo? Esta é uma das coisas mais desrespeitosas que você já disse. Toda a sua família e comunidade sofreu economicamente para que você fosse o primeiro, e agora você pode abrir possibilidades para novas gerações. Sua tarefa é trazer de volta o que você aprendeu pois, sem isso, o sacrifício é sem sentido".

Estou sendo muito pessoal com isso, mas minha resposta é exatamente esta: não podemos perder a capacidade de fazer crítica, mas temos de fazê-la como forma de apoio, estarmos abertos em receber críticas rigorosas, sem sermos arrogantes. Se não, agiremos como a direita. E esta é a fórmula do desastre.

\section{REFERÊNCIAS}

APPLE, Michael W. Ideologia e Currículo. $3^{\text {a }}$ edição. Porto Alegre: Artmed, 2006.

APPLE, Michael W. Conhecimento Oficial: a educação democrática numa era conservadora. Petrópolis, RJ: Vozes, 1997.

APPLE, Michael W. Escolas Democráticas. São Paulo: Cortez, 1997a.

APPLE, Michael W; BURAS, Kristen L (org.). Currículo, Poder e Lutas Educacionais: com a palavra, os subalternos. Porto Alegre: Artmed, 2008.

APPLE, Michael W.; AU, Wayne; GANDIM, Luís Armando (org.) Educação Crítica: análise internacional. Porto Alegre: Artmed, 2011.

APPLE, Michael W.; BALL, Stephen J.; GANDIM, Luís Armando (Org.). Sociologia da Educação: análise internacional. Porto Alegre: Penso, 2013.

APPLE, Michael W. Educating the "Right" Way: markets, standards, God, and inequality. $2^{\mathrm{a}}$ edição. Nova Iorque: Taylor \& Francis, 2006a.

APPLE, Michael W. A Educação pode mudar a sociedade? Petrópolis, RJ: Vozes, 2017.

GANDIN, Luís Armando. Criando alternativas reais às políticas neoliberais: a escola cidadã. IN: APPLE, Michael W; BURAS, Kristen L (org.). Currículo, Poder e Lutas Educacionais: com a palavra, os subalternos. Porto Alegre: Artmed, 2008.

GANDIN, Luís Armando; APPLE, Michael W. Mantendo transformações vivas aprendendo com o "Sul". IN: APPLE, Michael W. A Educação pode mudar a sociedade? Petrópolis, RJ: Vozes, 2017. 
'Notas de fim'

$1 \quad$ No original, Apple diz: "teachers must be held accountable".

$2 \quad$ Marcelo Crivella, eleito em 2017.

3 Apple refere-se às mudanças ocorridas durante a gestão do governo do Partido dos Trabalhadores no município de Porto Alegre (1989 a 2004), considerando a criação do orçamento participativo e especialmente no processo de gestão escolar, destacando-se o projeto Escola Cidadã (GANDIN, 2008). Mesmo após a posse de outros partidos, muitas dessas escolas mantêm o projeto em funcionamento, mesmo considerando os desafios para tal (GANDIN; APPLE, 2017).

4 O Fórum Social Mundial (FSM) é um espaço que foi criado por iniciativa de organizações não governamentais, movimentos sociais e sociedade civil para debater alternativas ao projeto econômico neoliberal, sendo pensado também como espaço de contraposição ao Fórum Econômico Mundial, realizado em Davos. O primeiro encontro foi realizado em 2001 na cidade de Porto Alegre, e teve como lema "Um outro mundo é possível". Os encontros do FSM ocorrem até hoje.

5 O professor Apple estava segurando uma garrafa de água neste momento, utilizando-a como analogia para explicar que se mantém a forma, mas muda-se o conteúdo.

6 O termo foi utilizado pelo professor Apple em sua palestra como uma crítica à postura que eventualmente pode ser tomada no trabalho junto às escolas, comunidades e outros espaços de pesquisa e/ou extensão. Por um lado, há a "esquerda retórica" que já teria as respostas do que deve ser feito, sem, no entanto, realizar um trabalho de base ou acompanhar as situações de exploração às quais denunciam. Tal postura, muitas vezes, busca ser evitada por acadêmicos/as simplesmente com suas presenças, sem uma crítica a eventuais problemas que possam ser percebidos. Nesse sentido, Apple comentou que mais do que o silêncio, que pode ser tão desrespeitoso quanto a postura arrogante, é fundamental a participação crítica nos espaços em que realizamos nossos trabalhos, considerando processos de escuta e acompanhamento. Nesse sentido, sugere-se o capítulo Paulo Freire e as tarefas do 
estudioso/ativista crítico na educação, presente no livro A Educação pode mudar a Sociedade? (APPLE, 2017, p. 47-82).

7 O professor Apple refere-se a esta entrevista que, conforme conversamos e planejamos, buscaria ser publicizada em diversos meios, sendo a primeira em publicação acadêmica, e outra em documentário, com o nome provisório de "Escola da Esperança", atualmente em produção.

Submetido: 20/07/2019

Aprovado: 13/11/2019

Contato:

Ricardo Gonçalves Severo

Universidade Federal do Rio Grande (FURG) Instituto de Ciências Humanas e da informação Av. Itália, km 8 - Bairro Carreiros Rio Grande |RS | Brasil

CEP 96.201-900 